\title{
Trauma Surgery Stop the Bleed: gap analysis and geographical evaluation of incident locations
}

\author{
Michelle Tsui, 1,2 Shannon L. Carroll, ${ }^{2}$ Daniel W. Dye, ${ }^{3}$ W. Andrew Smedley, ${ }^{2,4}$ \\ Aidan D. Gilbert, ${ }^{2}$ Russell L. Griffin, ${ }^{2,5}$ Gerald McGwin, ${ }^{5}$ Shannon W. Stephens, ${ }^{2}$ \\ Jeffrey D. Kerby (D, ${ }^{2}$ Jan 0 . Jansen (D) ${ }^{2}$
}

'Wide Base Hospital and Health Service, Bundaberg, Queensland, Australia ${ }^{2}$ Center for Injury Science, University of Alabama at Birmingham, Birmingham, Alabama, USA

${ }^{3}$ Department of Pathology, University of Alabama at Birmingham, Birmingham, Alabama, USA

${ }^{4}$ School of Medicine, University of Alabama at Birmingham, Birmingham, Alabama, USA ${ }^{5}$ Department of Epidemiology, University of Alabama at Birmingham, Birmingham, Alabama, USA

Correspondence to Dr Jan O. Jansen, Center for Injury Science, University of Alabama at Birmingham, 1922 7th Ave S, Birmingham, Alabama, USA; jjansen@uabmc. edu

Received 16 September 2019 Revised 6 November 2019 Accepted 23 December 2019

(c) Author(s) (or their employer(s)) 2020. Re-use permitted under CC BY-NC. No commercial re-use. See rights and permissions. Published by BMJ.

\section{To cite: Tsui M,}

Carroll SL, Dye DW, et al.

Trauma Surg Acute Care Open 2020:5:e000384.

\begin{abstract}
Background Trauma is a major public health issue. In 2015, the White House launched the "Stop the Bleed" (STB) campaign, which aims to equip would-be bystanders with the ability and equipment to assist in bleeding emergencies. This study sought to estimate the number of patients who might benefit from STB intervention, in an everyday setting, and their spatial injury profile.
\end{abstract}

Methods This is a retrospective analysis of trauma registry and medical examiners' data, collected between 2013 and 2017. The majority of patients were male. The median age was 32 years. Incidents were geocoded by ZIP code, and mapped using Quantum Geographic Information System (QGIS).

Results We identified 139 patients from medical examiner records and UAB's trauma registry who might have benefitted from STB intervention. The number of incidents per year ranged from 22 to 35 , averaging 2.3 incidents per month. There was no evidence of geographical clustering, although the small number of incidents precluded a formal geostatistical analysis. Conclusion The number of patients who might benefit from STB interventions on a daily basis is small, and incident locations are difficult to predict. Educating the public in how to stop bleeding is appealing, but providing easy and widespread access to STB kits may be difficult. Although there are parallels to the provision of cardiopulmonary resuscitation and defibrillation for cardiac arrest, there are also differences, which should not be overlooked.

\section{BACKGROUND}

Trauma is a major public health issue. Worldwide, approximately 5.8 million deaths result from trauma every year, and trauma is the leading cause of death in individuals aged 1 to 46 years. Bleeding is responsible for approximately one-third of trauma deaths, around one-fifth of which are thought to be preventable. ${ }^{2-4}$ The natural history of uncontrolled hemorrhage is cardiovascular collapse with consequent cerebral and myocardial hypoperfusion, ultimately leading to death. ${ }^{5}$ When hemorrhage is controlled expeditiously, patients often recover. ${ }^{6}$

Torso hemorrhage requires operative treatment or advanced interventions to control bleeding, but hemorrhage from the extremities can usually be controlled with relatively simple means, such as direct pressure, or the application of a tourniquet.
The "Stop the Bleed" (STB) initiative aims to train, equip, and empower those without medical training to assist in a bleeding emergency, through a combination of education and better access to equipment such as tourniquets and hemostatic dressings. ${ }^{7}$ The initiative has been likened to the widespread provision of automated external defibrillators (AED), to facilitate early defibrillation in patients with cardiac arrest due to ventricular fibrillation. The increasing frequency of mass casualty events, particularly those involving ballistic injuries, has heightened awareness of the problem of the importance of early hemorrhage control in the United States. ${ }^{8}$

Since the programme's inception, many community members have been trained in basic hemorrhage control techniques, and STB kits have been distributed to schools, churches, airports, malls, and many other locations. ${ }^{9}$ However, the kits are costly - prices range from $\$ 69$ to $\$ 950$ per unit $^{10}$ and many more kits will be required before accessibility will reach levels comparable to those of AED.

A more targeted approach to the selection of locations where the kits are most likely to be needed would be helpful. However, it is not known how many patients might benefit from STB interventions, and whether these incidents show evidence of geographical clustering. Given that sociological and environmental factors influences trauma occurrences, ${ }^{11} 12$ we hypothesized that geographical distribution of the resulting injuries might also occur in identifiable "hot spots".

The aim of this project was to conduct a geostatistical analysis of the number of injuries that might benefit from STB intervention, and their spatial injury profile, using a single county in the State of Alabama as a case study.

\section{METHODS}

We performed a retrospective analysis of trauma registry data from the level I trauma center at the University of Alabama at Birmingham (UAB) Hospital, and medical examiners' data from Jefferson County, Alabama. Jefferson County is the most populous county in the State of Alabama, with a population of approximately 660000 . UAB Hospital is the only level I trauma center in the region. We examined trauma incidents that occurred between 2013 and 2017. The study was approved by the Institutional Review Board. 
Table 1 Trauma registry case definitions

Injuries likely amenable to STB intervention, and would most likely need a tourniquet or advanced hemostatic dressing

\begin{tabular}{|c|c|c|c|}
\hline AIS Code & Description & AIS Code & Description \\
\hline \multicolumn{4}{|c|}{ Lower Extremity } \\
\hline 800999.9 & $\begin{array}{l}\text { Died of lower extremity injury without further } \\
\text { substantiation of injuries or no autopsy confirmation } \\
\text { of specific injuries }\end{array}$ & 813002.4 & Crush injury, at or above knee, below hip \\
\hline 811000.3 & $\begin{array}{l}\text { Amputation (traumatic), partial or complete between } \\
\text { hip and foot, but NFS as to specific anatomic sites }\end{array}$ & 813003.3 & Crush injury, below knee, at or above ankle \\
\hline 811003.3 & $\begin{array}{l}\text { Amputation (traumatic), below knee, at or above } \\
\text { ankle }\end{array}$ & 816006.3 & $\begin{array}{l}\text { Penetrating injury NFS, with blood loss }>20 \% \text { by } \\
\text { volume }\end{array}$ \\
\hline 820208.4 & $\begin{array}{l}\text { Femoral artery, major; rupture; transection; segmental } \\
\text { loss; blood loss }>20 \% \text { by volume }\end{array}$ & 816017.3 & $\begin{array}{l}\text { Penetrating injury at or above knee, with blood } \\
\text { loss }>20 \% \text { by volume }\end{array}$ \\
\hline 820608.3 & $\begin{array}{l}\text { Popliteal artery, major; rupture; transection; } \\
\text { segmental loss; blood loss }>20 \% \text { by volume }\end{array}$ & 810606.3 & $\begin{array}{l}\text { Skin/subcutaneous/muscle NFS, blood loss }>20 \% \\
\text { by volume }\end{array}$ \\
\hline 821008.3 & & 820806.3 & $\begin{array}{l}\text { Popliteal vein NFS, major; rupture; transection; } \\
\text { segmental loss; blood loss }>20 \% \text { by volume }\end{array}$ \\
\hline \multicolumn{4}{|c|}{ Upper Extremity } \\
\hline 700999.9 & $\begin{array}{l}\text { Died of upper extremity injury without further } \\
\text { substantiation of injuries or no autopsy confirmation } \\
\text { of specific injuries }\end{array}$ & 713002.4 & Crush injury, at or above elbow, below shoulder \\
\hline 711000.3 & $\begin{array}{l}\text { Amputation (traumatic), partial or complete between } \\
\text { shoulder and hand, but NFS as to specific anatomic } \\
\text { sites }\end{array}$ & 713003.3 & Crush injury, below elbow, at or above wrist \\
\hline 711002.4 & $\begin{array}{l}\text { Amputation (traumatic), at or above elbow, below } \\
\text { shoulder }\end{array}$ & 714001.3 & Degloving injury, entire extremity \\
\hline 711012.5 & Amputation (traumatic), bilateralc & 714002.2 & Degloving injury, arm or forearm, including elbow \\
\hline \multirow{2}{*}{721008.3} & & 720406.3 & $\begin{array}{l}\text { Axillary vein NFS, major; rupture; transection; } \\
\text { segmental loss; blood loss }>20 \% \text { by volume }\end{array}$ \\
\hline & & 720806.3 & $\begin{array}{l}\text { Brachial vein NFS, major; rupture; transection; } \\
\text { segmental loss; blood loss }>20 \% \text { by volume }\end{array}$ \\
\hline
\end{tabular}

STB, Stop the Bleed.

\section{Case definition}

We used abbreviated injury scale (AIS) codes to search the trauma registry for patients with injuries that might have been amenable to STB intervention such as tourniquet or advanced hemostatic dressing application (traumatic amputations major arterial injuries associated with marked blood loss) or direct pressure and simple dressings (crush and degloving injuries, venous injuries associated with marked blood loss). These injuries were mapped to AIS codes (table 1). Medical examiner's data, which are not AIS-coded, were reviewed manually to identify pre-hospital fatalities with extremity injuries that might have survived if STB interventions had been utilized.

\section{Analysis}

We extracted demographic, location, injury mechanism, injury severity, and outcome data for all patients. The data were
Injuries likely amenable to STB intervention, but would probably not benefit from tourniquet (needs dressing/direct pressure only)

Crush injury, at or above knee, below hip

Crush injury, below knee, at or above ankle

Degloving injury, entire extremity

Penetrating injury NFS, with blood loss $>20 \%$ by

Penetrating injury at or above knee, with blood loss $>20 \%$ by volume by volume

Femoral vein NFS, major; rupture; transection; Popliteal vein NFS, major; rupture; transection; segmental loss; blood loss $>20 \%$ by volume

egmental loss; blood loss $>20 \%$ by volume

summarized using descriptive statistics. Where the precise incident was not available, we used the place of residence, as most injuries occur at or close to home. ${ }^{13}{ }^{14}$ Incidents were geocoded by ZIP code, and analyzed using QGIS, an open-source geographical information systems software package. Patients injured outside of Jefferson County were excluded to ensure congruity between trauma center and medical examiner's data. The results are displayed as maps, showing both the crude number of incidents per ZIP code tabulation area (ZCTA), and the number of incidents per population per ZCTA.

\section{RESULTS}

During the 5 year period, there were a total of 139 patients who might have benefitted from STB interventions. Among all patients identified, 131 (94\%) were admitted to UAB's Trauma Center. The remaining $8(6 \%)$ individuals died without having 


\begin{tabular}{|c|c|}
\hline \multicolumn{2}{|l|}{ Source } \\
\hline Trauma registry, $\mathrm{n}(\%)$ & $131(94 \%)$ \\
\hline Medical examiner, $\mathrm{n}(\%)$ & $8(6 \%)$ \\
\hline \multicolumn{2}{|l|}{ Year injured } \\
\hline $2013, \mathrm{n}(\%)$ & $27(19 \%)$ \\
\hline $2014, \mathrm{n}(\%)$ & $27(19 \%)$ \\
\hline $2015, \mathrm{n}(\%)$ & $22(16 \%)$ \\
\hline $2016, \mathrm{n}(\%)$ & $28(20 \%)$ \\
\hline $2017, \mathrm{n}(\%)$ & $35(25 \%)$ \\
\hline \multicolumn{2}{|l|}{ Demographics } \\
\hline Age, years, median (IQR) & $32(25-50)$ \\
\hline Male gender, $\mathrm{n}(\%)$ & $118(85 \%)$ \\
\hline \multicolumn{2}{|l|}{ Mechanism } \\
\hline Penetrating/ballistic, n (\%) & $54(39 \%)$ \\
\hline Penetrating/non-ballistic, n (\%) & $11(8 \%)$ \\
\hline Blunt, $\mathrm{n}(\%)$ & $74(53 \%)$ \\
\hline \multicolumn{2}{|l|}{ Injury sites } \\
\hline Upper extremity, n (\%) & $54(39 \%)$ \\
\hline Lower extremity, n (\%) & $85(61 \%)$ \\
\hline \multicolumn{2}{|l|}{ Injury types } \\
\hline Likely need for tourniquet or advanced hemostatics, n (\%) & $77(55 \%)$ \\
\hline Probably no need for tourniquet or advanced hemostatics, $\mathrm{n}(\%)$ & $62(45 \%)$ \\
\hline \multicolumn{2}{|l|}{ Injury severity* } \\
\hline Injury severity score, median (IQR) & $14(9.0-20.5)$ \\
\hline Injury severity score >15, n (\%) & $67(48 \%)$ \\
\hline \multicolumn{2}{|l|}{ Outcome } \\
\hline Prehospital death, n (\%) & $8(6 \%)$ \\
\hline Inhospital death, n (\%) & $18(13 \%)$ \\
\hline Survived, n (\%) & $113(81 \%)$ \\
\hline
\end{tabular}

*trauma registry patients only.

contact with medical services. Additionally, 18 (14\%) of the patients admitted to hospital died. The number of incidents per year ranged from 22 to 35, averaging 2.3 incidents per month.

The baseline characteristics of the study group are shown in table 2 . The majority of the patients $(85 \%)$ were male and the median age was 32 years (IQR 25 to 50 ). A median injury severity score of 14 (IQR 9.0 to 20.5) was observed, whereas a total of $67(48 \%)$ injuries had an injury severity score $>15$. Most patients (53\%) sustained blunt trauma, whereas 65 (47\%) sustained penetrating injuries. Of the 65 penetrating injuries, $54(83 \%)$ were ballistic (gunshot) injuries, whereas 11 (17\%) patients were non-ballistic.

All injuries were limited to the extremities, with 85 (61\%) sustaining injuries to the lower extremities, and 54 (39\%) to the upper extremities. Among all injuries, 77 (55\%) involved arterial damage or traumatic amputation, which would most likely have required a tourniquet or advanced hemostatic to control hemorrhage. Conversely, $62(45 \%)$ of the injuries were venous or degloving injuries, which could have been controlled by simpler means.

Figure 1 shows the geographical distribution of traumatic hemorrhage incidents. The crude number of incidents, denoted by blue circles, varied from 0 to 11 per ZCTA.

The number of incidents per population is shown by area color-coding, and ranged from 0 to 1.27 incidents per 1000 population (during the 5 -year study period). The central areas

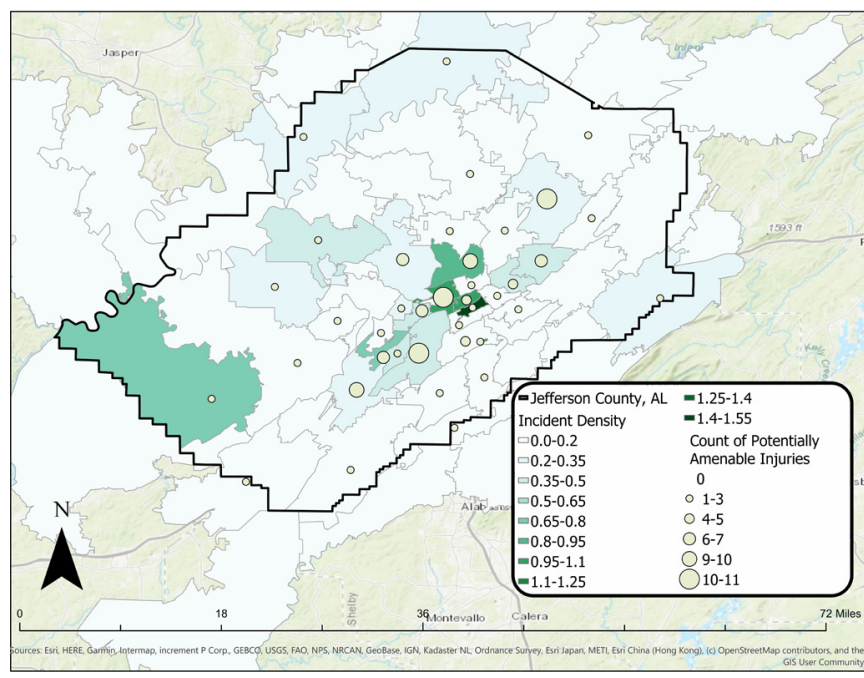

Figure 1 Map of Jefferson County, showing number of patients with injuries potentially amenable to "stop the bleed" intervention (yellow circles), as well as the number of such injuries per population (by ZIP code tabulation area, shaded). please note that the ZIP code tabulation areas and County boundary are not congruous.

of the county, corresponding to the central Birmingham, appear to have a higher incidence rate. However, the geographical distribution beyond this area is heterogeneous, with no identifiable geographical patterns or differences between ZCTAs. The number of incidents per areal unit were too small to conduct a formal statistical comparison.

\section{DISCUSSION}

This study was originally conceived as a "siting project", to inform the placement of STB kits where they are most likely to be needed. However, our results demonstrate that the number of patients who suffer injuries that might benefit from STB interventions in Jefferson County is small; and that the geographical locations of these incidents are not easily predictable.

These findings raise important questions regarding the aims of the STB Programme. The initiative was launched in the aftermath of the Sandy Hook shootings, and similar mass casualty events. ${ }^{7}$ It attempts to transfer the lessons learnt during the wars in Afghanistan and Iraq, relating to early hemorrhage control and the use of tourniquets, to the civilian setting. ${ }^{.}$The programme seeks to inform, educate, and empower would-be bystanders to serve as immediate responders to save lives by control of hemorrhage at the scene of injury.

These aims have invariably invited comparisons to cardiopulmonary resuscitation for (medical) cardiac arrests, and public access to AED. Although there are similarities, our findings highlight that there are also important differences. Publicly available data from the Alabama Department of Public Health, for a period of 21 months (January 2018 to September 2019) shows that there were 354 incidences where an AED had been applied, prior to the arrival of Emergency Medical Services, in Jefferson County. This equates to 16.8 AED uses per month, more than seven times the predicted rate of STB interventions identified in this study. (G. Varner, personal communication, October 23, 2019) Both public health campaigns can be regarded as consisting of a "skill" component (application of direct or indirect pressure for external hemorrhage, initiation of chest compressions for medical cardiac arrest) and an "equipment" component (provision of tourniquets and hemostatic 
dressings for controlling hemorrhage, and provision of AED for cardioversion). Providing education in how to stop bleeding and perform chest compressions correctly is associated with few disadvantages. The provision of equipment, in contrast, is more complex, because it is associated with higher costs. These public health interventions should ideally be shown to be effective - as the provision of AED has.

The biggest difference between the two programme, as evidenced by their origins, however, lies in the fact that mass shooting events can result in unpredictable clusters of large numbers of patients requiring STB interventions - and large numbers of tourniquets and hemostatic dressings. There is no equivalent of medical cardiac arrests occurring en masse. Philosophically, the STB campaign needs to decide whether it aims to prepare high-risk locations such as schools, colleges, malls and places of worship with the skills and equipment to deal with a rare event, or whether it intends to improve the survival of patients injured in isolated, everyday incidents.

This was a retrospective study, conducted in a single county, and therefore has limitations. Injuries abstracted from a trauma registry or medical examiners' records may not accurately reflect what the public or emergency medical service providers would do when faced with external hemorrhage. There is also the possibility that we are not capturing all potential patients in the county. Some patients may not have sought medical attention and some may have been taken to other hospitals. However, $\mathrm{UAB}$ is the only level I trauma center in the region thus it is expected that most patients with difficult-to-control hemorrhage to be taken to our center.

\section{CONCLUSION}

In our setting, the number of patients who might benefit from STB interventions appears to be small, and their locations are not easily predicted. Consideration should be given as to whether STB is primarily intended to address the consequences of a mass casualty event, or whether it should be available to all.

Contributors JJ, RG and JDK conceived the idea for this study. RG and DD extracted the data. RG, AG, JJ and MT conducted the analysis. All authors contributed to the interpretation and writing of the article.

Funding The authors have not declared a specific grant for this research from any funding agency in the public, commercial or not-for-profit sectors.

Competing interests None declared.
Patient consent for publication Not required.

Provenance and peer review Not commissioned; externally peer reviewed.

Data availability statement No data are available.

Open access This is an open access article distributed in accordance with the Creative Commons Attribution Non Commercial (CC BY-NC 4.0) license, which permits others to distribute, remix, adapt, build upon this work non-commercially, and license their derivative works on different terms, provided the original work is properly cited, appropriate credit is given, any changes made indicated, and the use is non-commercial. See: http://creativecommons.org/licenses/by-nc/4.0/.

\section{ORCID iDs}

Jeffrey D. Kerby http://orcid.org/0000-0001-7368-1124

Jan 0. Jansen http://orcid.org/0000-0001-8863-4398

\section{REFERENCES}

1 World Health Organization. Injuries and violence: the facts. https://www.who.int/ violence_injury_prevention/key_facts/en/ (Oct 2018).

2 Davis JS, Satahoo SS, Butler FK, Dermer H, Naranjo D, Julien K, Van Haren RM, Namias $\mathrm{N}$, Blackbourne LH, Schulman $\mathrm{Cl}$. An analysis of prehospital deaths: who can we save? J Trauma Acute Care Surg 2014;77:213-8.

3 Tien HC, Spencer F, Tremblay LN, Rizoli SB, Brenneman FD. Preventable deaths from hemorrhage at a level I Canadian trauma center. J Trauma 2007;62:142-6.

4 National Academies of Sciences, Engineering, and Medicine. A national trauma care system: integrating military and civilian trauma systems to achieve zero preventable deaths after injury. Washington, DC: The National Academies Press, 2016.

5 Peitzman AB, Billiar TR, Harbrecht BG, Kelly E, Udekwu AO, Simmons RL. Hemorrhagic shock. Curr Prob/ Surg 1995;32:925-1002.

6 Kauvar DS, Lefering R, Wade CE. Impact of hemorrhage on trauma outcome: an overview of epidemiology, clinical presentations, and therapeutic considerations. J Trauma 2006;60:S3-11.

7 Bulger EM, Gestring ML, Jacobs LM. Optimizing bleeding control training for the public: a national imperative. JAMA Surg 2018;153:799.

8 Knudson MM, Velmahos G, Cooper ZR. Response to mass casualty events: from the battlefield to the stop the bleed campaign. Trauma Surg Acute Care Open 2016;1:e000023.

92018 Progress Report. Bleeding Control. https://www.bleedingcontrol.org/about-bc/ progress-report (Accessed 26 Jan 2019).

10 Bleeding Control Store. https://controlbleedingkits.com/ (Accessed 23 Jan 2019).

11 Lawson F, Schuurman N, Amram O, Nathens AB. A geospatial analysis of the relationship between neighbourhood socioeconomic status and adult severe injury in Greater Vancouver. Inj Prev 2015;21:260-5.

12 Smith MR, Davis RL, Phillips PA, Shvilkina T, Kaur K, Tabolt HK, Krause M, Galdi V. Geographical information system evaluation and trends of Nonaccidental trauma at a level I trauma center, pilot study. Ann Surg 2017;265:418-23.

13 Haas B, Doumouras AG, Gomez D, de Mestral C, Boyes DM, Morrison L, Nathens AB. Close to home: an analysis of the relationship between location of residence and location of injury. J Trauma Acute Care Surg 2015;78:860-5.

14 Jansen JO, Morrison JJ, Wang H, He S, Lawrenson R, Campbell MK, Green DR. Feasibility and utility of population-level geospatial injury profiling: prospective, national cohort study. J Trauma Acute Care Surg 2015;78:962-9. 